\title{
Palliative Care for Patients with Advanced Cancer
}

\author{
Dra Mirta D Ambra* \\ Ministry of Health Specialist, University of Bs As, Argentina
}

Received: 眥 May 21, 2018; Published: 啙 May 31, 2018

*Corresponding author: Dra Mirta D Ambra, Chairman in Argentina World Academy Medical Sciences (WAMS), Ministry of Health Specialist, University of Bs As, Argentina

\section{Mini Review}

The diagnosis of cancer or other serious diseases causes a great impact to patients and their families. As the disease progresses and the healing possibilities are exhausted, invalidating symptoms may appear as well as innumerable problems that deserve attention and care, as they affect the quality of life of the patient. It is part of the treatment to accompany our patients and their families through the whole disease from the medical knowledge, empathizing with the patient, in order to offer the necessary resources to go through the process. It is necessary to have a qualified team to cover all the affected areas in it.

\section{What is Palliative Care?}

Palliative care is part of a comprehensive treatment for the care of discomfort, physical, mental and emotional symptoms, of all serious and chronic diseases, and of what is important in the life of the patient and his family. They do not replace the primary treatment, but contribute to it. Its goal is to prevent, alleviate suffering, improve their quality of life, and listen to the particular needs of the patient and their environment. The objective of palliative care is to treat the pressing symptoms such as pain, breathing difficulties or nausea and anguish, among others. To provide full and active assistance by an interdisciplinary team, to patients and their environment, when there is no chance of cure.

\section{How is the Treatment?}

Palliative care provides support to the patient and his family and can improve communication between him and his doctors / social work, allowing him to include his particular needs in the process to travel.

\section{Palliative Care Offers}

Specialized treatment to relieve pain and other symptoms as much as possible.

An open dialogue about therapeutic options, which include the treatment of your disease and the control of symptoms. Emotional support for the patient and his family. New research shows that patients who receive this type of care say they have an improvement in:

a) Pain and other pressing symptoms, such as nausea, breathing problems, stress, etc.

b) Communication with your doctors / health system and family.

c) Emotional support

d) Quality of life

\section{Other Studies also Show that Palliative Care}

a) They ensure that attention is focused more on the patient's wishes.

b) They meet the emotional and spiritual needs of patients.

c) When should it start?

d) Many people who live with diseases such as cancer, heart disease, COPD, kidney failure, or AIDS, among others, suffer physical symptoms and emotional discomfort related to their illnesses. Sometimes, these symptoms have to do with the medical treatments they receive.

\section{Palliative Care Can be Considered in the Following} Cases

a) Suffer pain or other symptoms because of any serious illness.

b) Feel physical or emotional pain that is NOT controlled.

c) He needs help to understand his situation and coordinate his attention.

d) It is never too early to start receiving palliative care, the patient should receive them as soon as they are needed. In 
fact, palliative care is given at the same time as the $r$ rest of the treatments for their disease and do not depend on the progress of it. There is no reason to wait, when they can be contacted early, the symptoms get better control and the process proceeds with greater comfort.

Serious illnesses and their treatments can cause great fatigue, anxiety and depression. The palliative care teams know that pain and other symptoms affect the quality of life and can take away from the patient the energy or motivation to continue doing the things that they like. In addition, they know that the stress they are suffering can profoundly affect their family. Our professionals can help you cope with this difficult experience by participating in finding the best way to care for and accompany you. Not all oncology services offer palliative treatments; Generally, because of a cost issue in Health that the Institutions intend to ignore. However, improve the quality of life of the terminal patient and his family. It is part of complementing a treatment, perhaps in a way that we do not like.

\section{(c) \\ This work is licensed under Creative Commons Attribution 4.0 License}

To Submit Your Article Click Here : Submit Article

DOI: $10.32474 /$ RRHOAJ.2018.02.000130

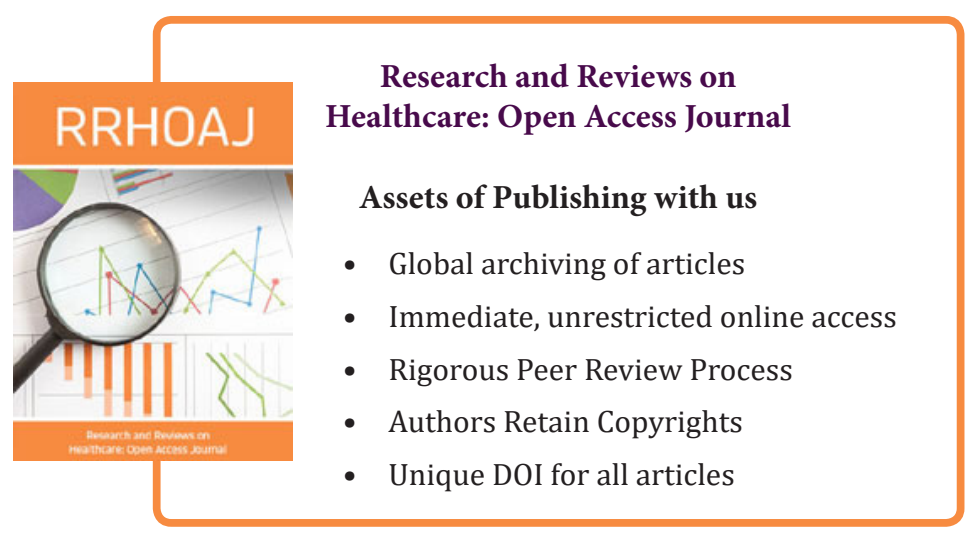

